\title{
LEAN SIGMA AND SIMULATION, SO WHAT'S THE CORRELATION? V2
}

\author{
David M. Ferrin \\ Business Prototyping Inc. \\ 1004 Creekside Circle \\ Naperville, IL 60563, U.S.A.
}

\author{
Martin J. Miller \\ Business Prototyping Inc. \\ 3113 Coventry East \\ Safety Harbor, FL 34695, U.S.A.
}

\author{
David Muthler \\ PWC Consulting \\ 705 Mulberry Court \\ Naperville, IL 60540, U.S.A.
}

\begin{abstract}
This paper will explore the fundamental relationships between Lean Sigma and simulation. A basic overview of Lean Sigma includes: 1) Lean Sigma philosophy, 2) Basic tools, 3) Theory of Variation, 4) SPC, 5) Process capability,6) Lean Sigma infrastructure, and 7) DMAIC and DFSS processes. Simulation will be applied to the appropriate areas of the overview. Improvement in the robustness of the Lean Sigma methodology will be discussed and the strengths of simulation will be presented as capable and preferable enhancements to the Lean Sigma processes. Quotes from Lean Sigma and industry leaders will be presented. Simulation will be presented as an innovation tool enhancing the Lean Sigma DMAIC and DFSS processes.
\end{abstract}

\section{LEAN SIGMA OVERVIEW}

Developed initially by the Japanese manufacturing industry, Lean, as a management strategy, has evolved from the Kaizen philosophy of constant improvement. The mastery of Kaizen, resulting in revolutionary products with unbeatable prices on the world market, was a main contributor to Japan's economic success from the late 1950s to the early 1990s. Toyota is a great example of this. Toyota has understood not only how to master Lean within its manufacturing plants, but also how to transfer the concept successfully to the entire supply chain, from suppliers to dealerships, and on top of that to all of the supporting processes.

Lean means eliminating waste from any process or product. The first step is to identify the true Value Stream of a business process. A clearly defined and agreed upon Value Stream throughout the organization is the basis for any improvement action to achieve high process performance at a significantly reduced cost base.

Conceptually, the business processes in Lean are viewed from the customer's perspective. The value of an activity is solely defined by the customer. Activities that add value to the customer are those that make the product or service resemble more of what the customer actually wants and for which he is willing to pay. Non value-added activities, however, do not create any value for the customer, and therefore all nonessential, non-value-added activities are considered as waste. Waste is any activity in the workflow that adds time, effort or cost but does not create value.

Six Sigma has received wide acclaim as a methodology, process and vision to accomplish process improvement. Professor Larry S. Aft, PE, Chairman of the Industrial Engineering Department at Southern Polytechnic State University in a course delivered through the Center for Quality Excellence entitled Six Sigma Implementation, Champion and Green Belt Training states, "Six Sigma is a customer focused, well defined problem solving methodology supported by a handful of powerful statistical tools." He further states, "Continuous improvement is driven by the execution of carefully selected projects. The goal of the Six Sigma approach is to take small steps forward and no steps backward." Aft further states that "the objective of Six Sigma is to reduce variation through continuous process improvement. This leads to customer satisfaction."

Motorola was instrumental in the initiation of Six Sigma. In fact, the phrase "Six Sigma" was coined by Motorola. They further stated that a defect is anything that results in customer dissatisfaction.

General Electric (GE) has become an avid supporter of Six Sigma over recent years. According to their website, Six Sigma is not a "secret society, a slogan or a cliché. Six Sigma is a highly disciplined process that helps us focus on developing and delivering near-perfect products and services."

They further state that the word "sigma" is a statistical term that measures how far a given process deviates from perfection. The central idea behind Six Sigma is that if you can measure how many "defect's you have in a process, you can systematically figure out how to eliminate them and get as close to "zero defects" as possible. To achieve Six Sigma quality, a process must produce no more than 3.4 defects per million opportunities. An "opportunity" is defined as a chance for nonconformance, or not meeting the required specifications. This means we (GE) need to be nearly flawless in executing our key processes." 
Aft states that three sigma quality is $99.73 \%$ defect free. That implies that in a three sigma world, there would be approximately 54,000 incorrect drug prescriptions per year and 40,500 babies dropped in the delivery room each year in the United States. In a Six Sigma quality world, there would be only one incorrect drug prescription every 25 years and three newborn babies dropped every century. These examples illustrate well the differences in producing defect free work under the traditional three sigma constraints versus the more aggressive, customer oriented Six Sigma requirements.

GE states that "Six Sigma is embedding quality thinking, process thinking across every level and in every operation of our company around the globe. Today, Six Sigma is the way we work. It is a vision we strive toward and a philosophy that is part of our business culture. It has changed the DNA of GE and has set the stage for making our customers feel Six Sigma."

The key concepts of Six Sigma are:

1. Critical to Quality (CTQ) - Attributes most important to the customer

2. Defect - failing to deliver what the customer wants

3. Process Capability - What your process can deliver

4. Variation - What the customer sees and feels

5. Stable Operations - Ensuring consistent, predictable processes to improve what the customer sees and feels

Six Sigma is divided into two methodologies, DMAIC and DFSS. DMAIC (which is an acronym for Define, Measure, Analyze, Improve, Control) focuses on improving existing processes and performance. While Design for Six Sigma (DFSS) focuses on generating new processes, products, services, and/or plants to meet customer needs (CTQ) at the Six Sigma level.

The Seven Basic Tools of DMAIC are:

1. Flow charts

2. Check sheets

3. Pareto diagrams

4. Cause/Effect diagrams

5. Scatter diagrams

6. Histograms

7. Statistical Process Control (SPC).

DFSS uses many of the above tools with the addition of:

1. Affinity Diagram

2. Quality Function Deployment

3. Design of Experiments

4. Tree Diagrams

5. Activity Networks
6. Prioritization Matrices

7. Failure Mode and Effects Analysis

8. Multi Generation Project Plan

9. Scorecards

10. Risk Analysis

11. Simulation

Six Sigma has an inherent organization structure relating to its implementation processes. It includes:

- Steering Committee

- Champions

- Green Belts

- Black Belts

- Master Black Belts.

The steering committee is usually responsible for identifying projects, identifying black belts, allocating resources, monitoring progress, reviewing effectiveness, and establishing implementation strategy and policies. Composition of the group is usually senior level executives.

Champions are key management personnel who provide support and resources for the process. They require a more in-depth understanding of the methods used, especially the measurements and the interpretation of the process measurements.

A Green Belt is an introductory participant in the Six Sigma process; they understand concepts of data collection and data interpretation. At GE, they are similar to Black Belts, but are not a full-time position dedicated to the Six Sigma process.

Black Belts are thoroughly trained individuals expert in all of the analysis tools. Their training is typically structured around a project where the analysis tools are applied as part of the training process. Black Belts teach, coach, transfer knowledge, identify opportunities, and influence the organizational use of Six Sigma methods. At GE, they are leaders of teams responsible for measuring, analyzing, improving and controlling key processes that influence customer satisfaction and/or productivity growth. GE Black Belts are full-time positions dedicated to their Six Sigma processes.

Master Black Belts have demonstrated proficiency by documenting savings in excess of a predetermined amount. The title is one given as recognition for outstanding performance. In the GE context, Master Black Belts are first and foremost teachers. They review and mentor Black Belts. Selection criteria for Master Black Belts are quantitative skills and the ability to teach and mentor. Master Black Belts are full-time positions dedicated to their Six Sigma processes, as are GE Black Belts.

In summary:

- $\quad$ Lean $=$ Improved process flow

- Six Sigma $=$ Reduced process variation. 
Lean Sigma means to merge these two separate disciplines into a single entity. Lean Sigma is the next logical step in the continuous improvement journey. Table 1 lists some of the characteristics of the two disciplines.

Table 1: Characteristics of Six Sigma and Lean Strategies

$\begin{array}{ll}\text { SixSigma } & \text { Lean } \\ \begin{array}{l}\text { Eliminate defects as defined } \\ \text { by the customer }\end{array} & \begin{array}{l}\text { Focus on maximizing } \\ \text { process velocity }\end{array} \\ \begin{array}{l}\text { Recognizes that variations } \\ \text { hinder our ability to reliably } \\ \text { deliver high quality products }\end{array} & \begin{array}{l}\text { Tools for analyzing } \\ \text { process flows and de- }\end{array} \\ \begin{array}{l}\text { Requires data-driven deci- } \\ \text { sions }\end{array} & \begin{array}{l}\text { Centers on value added } \\ \text { vs non-value added }\end{array} \\ \begin{array}{l}\text { Set tools for effective prob- } \\ \text { lem solving }\end{array} & \begin{array}{l}\text { Means for quantifying } \\ \text { and eliminating com- } \\ \text { plexity }\end{array}\end{array}$

\section{SIMULATION'S FIT IN LEAN SIGMA}

In regards to DMAIC in the previous Lean Sigma overview, Aft is quoted as saying that " Lean Sigma is a customer focused, well defined problem solving methodology supported by a handful of powerful statistical tools." In a true statistical sense, the supporting tools are most commonly used by individuals with less than Green belt training. More advanced techniques are used by the Black Belts and Master Black Belts including linear and multivariate regression and design of experiments. However, as statistically powerful as these tools are they pale by comparison to the synergy and capability of simulation. Moreover, the statistical rigor available through valid, verifiable simulation efforts is an extremely compatible "fit" philosophically for Lean Sigma. If one was to compare defects in the Lean Sigma analysis process, simulation would be much more capable of predicting Lean Sigma tolerances. Other "lighter tools" often used in Lean Sigma would not be as "robust" and consequently would not give you the confidence in relation to the solution.

In regards to measuring customer satisfaction, simulation is one of the few tools capable of measuring financial indicators, operational indicators and customer satisfaction indicators in the same analysis. Moreover, in measuring CTQ attributes, sensitivity analysis performed through a valid simulation is an excellent methodology identifying the most appropriate CTQ impacting the process under review. This can usually be done quicker and more economically than using the high power statistical tools like Design of Experiments.

For GE, Design for Six Sigma is a systematic methodology utilizing tools, training, and measurements to enable one to design products and processes that meet customer expectations that can be produced at Lean Sigma quality levels. Simulation is a well designed capability that brings the statistically robust solution and associated confidence to meet the customers' expectations that a process will deliver at Lean Sigma quality levels. It is one of the few, elite tools capable of delivering a true Lean Sigma solution that is accurate. One might say that simulation is a $6 \sigma \mathrm{ca}-$ pable tool. In other words, simulation is a tool capable of $6 \sigma$ accuracy in the analysis itself. This does not mean that every simulation is inheritably valid. In fact, one of the main issues and most difficult aspects of simulation is verification and validation of the model. What is meant by a $6 \sigma$ capable tool is that the tool, simulation, is capable of delivering an answer that is highly accurate and defect free.

Gerald J. Hahn and Necip Doganaksoy, GE Corporate R \& D and Roger Hoerl, GE Corporate Audit Staff in "The Evolution of Lean Sigma" Quality Engineering, stated, "Simulation allows one to build a model of a process or system on a computer and to use computer evaluations to assess the impact of alternative strategies. Thus, simulation has traditionally been used to model the building of a product in a factory and to assess the impact on the time to manufacture of adding further equipment or personnel. Similarly, simulation can be used to assess business processes, such as the impact on customer waiting time of adding people to staff a product telephone "hot line." Also, simulation provides an attractive alternative to more formal statistical analyses in, for example, assessing how large a sample is required to achieve a specified level of precision in a market survey or in a product life test." Simulation is becoming more of a mainstay decision analysis process due to its ability to deliver robust answers to difficult business questions.

In support of this statement, Robert Crosslin in "Simulation, The Key to Designing and Justifying Business Reengineering Projects" The Electronic College of Process Innovation stated that "virtually all of the Fortune 50, a majority of the Fortune 1000 and military planning units of all technologically advanced countries, use simulation rather than subjective notions to make decisions about key manufacturing and logistics process decisions. There are no good reasons why simulation should not be used to aid decisions about key business processes. On the contrary, there are numerous good reasons why simulation should be used for BPR." Industry analyst Gartner, August 7, 2000 stated, "Simulation and animation technology offers ... organizations the potential to more rigorously test, analyze, validate and communicate their business processes and systems before they invest in implementation" (Kleinberg 2000a). They further stated on October 27, 2000 “...organizations have a long history of efforts in quality and process improvement, but the efforts often have been costly, cumbersome and frequently of limited success...Process-modeling, simulation and workflow software enables (organizations) to examine assumptions, de- 
pendencies and time frames before investments are made. Solutions can then be implemented in ways that empower, not hinder, knowledge workers and their ability to handle complex tasks" (Kleinberg 200b). Simulation is becoming a tool of choice for the corporate sector when a solution must be correct and error is not tolerated.

Simulation is appropriate for and may even be preferred for use in many of the DMAIC stages. In the Measure phase, the objective is to determine where one is relative to desired objectives, identify critical quality characteristics and estimate current capability. Traditional tools for this stage are cost of quality (appraisal, detection, failure), process capability (percent nonconforming, capability indices), and measurement systems analysis. As mentioned earlier, simulation is likely an improved tool to determine through sensitivity analysis, the true drivers are critical to quality characteristics, CTQ. Simulation is also a superior tool to determine the capability of the current processes. Other mechanisms rely upon benchmarks that may be ill advised or even inappropriate.

In the Analyze phase, the objective is to show the amount of improvement that might be possible to make the critical quality characteristic "best in class." Traditional analysis tools are descriptive statistics, inferential statistics, probability, and analysis of means. While traditional tools may be adequate to analyze and determine the future potential/capability of a process, simulation is the best way to accurately identify with statistical validity, the capability of a to-be process. It is the best tool, possibly the only analysis tool, capable of delivering Lean Sigma accuracy of the to-be process.

In the Improvement phase, the objective is that possible improvements are implemented and evaluated in a logical and planned fashion. Traditional tools are project management, correlation, regression (linear, multivariate), design of experiments (ANOVA, factorial). In evaluating the value proposition of possible improvements, simulation is again the only analysis tool capable of delivering Lean Sigma accuracy of the possible improvements.

In the Control phase, the objective is to ensure that measures are put into place to maintain improvements. Traditional tools are SPC, cost of quality and ISO 9000. Simulation is one of the few tools that can prototype a possible solution in an SPC format. Outputs are available that can show if a process is statistically in control or not in control as well as determine the defects outside the upper and lower control limits. It allows one to ensure that the measures chosen in fact perform as intended and reflect the correlation with the possible improvements.

\section{ADDED BENEFITS OF SIMULATION FOR LEAN SIGMA EFFORTS}

While traditional tools are helpful in determining possible improvements, simulation brings a new level of innovation to the table. Stephen Shapiro in "24/7 Innovation, A Blueprint for Surviving and Thriving in an Age of Change" Chapter 8, Simulating New Models, he states, "Misguided innovation can be costly in time and money and in trust between manager and employee. How can these risks be contained? Many companies find that simulation is the answer. It is only in recent years that (simulation) has become sophisticated enough to fully test innovative solutions before actually implementing them in the business. In my experience, the refinement of an idea through computerized simulation is the best route to preimplementation testing. It allows us to approach, if not achieve, perfection prior to betting the business on it." Simulation helps a team focus on the solutions that have the most potential improvement value and further refine those scenarios that will help. It brings a higher level of innovation and focuses a team's innovation energy on the best solutions.

\section{CONCLUSION}

Simulation is a good fit for Lean Sigma, DFSS and DMAIC. It is used by many of the world's "best" companies when their answers must be right the first time. Moreover, from a Lean Sigma philosophical perspective, simulation is an excellent tool capable of providing Lean Sigma quality analytical prowess. It is a $6 \sigma$ capable tool. Simulation has earned a place in Lean Sigma culture and will continue to be a valued tool in delivering customer focused, well defined solutions. It will continue to help companies take small and large steps forward and no steps backward, reducing variation through continuous process improvement while leading teams to improved customer satisfaction.

\section{REFERENCES}

The Agility Group, University of Durham, 2003. Lean Sigma . [online] <http: // www. onesixsigma . com/experence/white_papers/integrati ng_six_sigma.php/> [accessed August, 2005]

Dirk RRoettgest, Venturehaus Limited 2003. Six Sigma or Lean? How to get the best of both worlds. [online]

<http:// Www.onesixsigma.com/ experience/white_papers/integrating_six_si gma . php / > [accessed August, 2005]

Aft PE, Larry S. 2001. Lean Sigma implementation, Champion and green belt training, Course instruction, Center for Quality Excellence, Southern Polytechnic State University.

Crosslin, Robert, 1995. Simulation, The key to designing and justifying business reengineering projects, The Electronic College of Process Innovation. 
General Electric Company, 2002. What Is Lean Sigma?, The roadmap to customer impact [online]. <http://www.ge.com/sixsigma/> [accessed July 15, 2002]

Kleinberg, Kenneth. 2000a. Simulation and animation technology for healthcare, Strategy \& Tactics/Trends \& Directions. Gartner, Inc.

Kleinberg, Kenneth. 2000b. Simulation of emergency rooms at VHA, Best Practices and Case Studies. Gartner, Inc.

Hahn, Gerald J., Necip Doganaksoy, and Roger Hoerl, GE Corporate, The evolution of lean sigma" Quality Engineering, Volume 12, Number 3.

Shapiro, Stephen M. 2002. 24/7 Innovation, A blueprint for surviving and thriving in an age of change. Hightstown, NJ: McGraw-Hill.

\section{AUTHOR BIOGRAPHIES}

DAVID M. FERRIN, FHIMSS is President and founder of Business Prototyping Inc. He was previously an Associate Partner with Accenture's Capability Modeling and Simulation practice in Northbrook, Illinois where he served as the Lead of the America's practice. David was an Assistant Professor in the Health Systems Management department at Rush University, Chicago, Illinois and is an Adjunct Professor in the Health Records Administration department at York College, York, Pennsylvania. He is a Senior Member and past chapter president of IIE and a Fellow Member and past chapter president of HIMSS. David has served/serves on Winter Simulation Conference committees since 1997. In 2003 he was the WSC general chair. He is a frequent speaker on simulation and quality in health care and has 25 years experience in those areas. David holds a BSIE degree from the University of Utah and an MHA degree from Brigham Young University. David is a Six Sigma Black Belt. His email address is <dferrinabizproto.biz>.
MARTIN J. MILLER is a Senior Manager for Business Prototyping Inc. He previously worked over eight years for Accenture and was a Manager for their Capability Modeling And Simulation practice. He also led the development and testing of software applications for the utilities industry. He obtained his CMM for Software certification from the Software Engineering Institute in 1998. He received his Masters of Science in Industrial \& System Engineering and Bachelors of Science in Aerospace Engineering from the University of Florida. His email address is <mmiller@bizproto.biz>.

DAVID MUTHLER is a Principal Consultant at PwC in the Center of Excellence--Lean Sigma. He has over 30 years experience in Operations and Process Improvement. Dave has successfully applied both the DMAIC and DMADV in a range of industries in manufacturing and non-manufacturing. Clients include: military, government, pharmaceutical, healthcare, retail, airlines, and automotive. Dave has an M.S. in Industrial Engineering/Operations Research (major in Statistics) from Wayne State University, an MBA in Finance/Management and a B.S. in Mathematics from Xavier University. Dave is a Certified Quality Engineer and a Lean Sigma Master Black Belt. His e-mail address

is 